\title{
Improving global paleogeography since the late Paleozoic using paleobiology
}

\author{
Wenchao Cao $^{1}$, Sabin Zahirovic ${ }^{1}$, Nicolas Flament ${ }^{1, a}$, Simon Williams ${ }^{1}$, Jan Golonka ${ }^{2}$, and R. Dietmar Müller ${ }^{1,3}$ \\ ${ }^{1}$ EarthByte Group and Basin GENESIS Hub, School of Geosciences, The University of Sydney, \\ Sydney, NSW 2006, Australia \\ ${ }^{2}$ Faculty of Geology, Geophysics and Environmental Protection, AGH University of Science and Technology, \\ Mickiewicza 30, 30-059 Kraków, Poland \\ ${ }^{3}$ Sydney Informatics Hub, The University of Sydney, Sydney, NSW 2006, Australia \\ acurrent address: School of Earth and Environmental Sciences, University of Wollongong, \\ Northfields Avenue, Wollongong, NSW 2522, Australia \\ Correspondence to: Wenchao Cao (wenchao.cao@sydney.edu.au)
}

Received: 16 March 2017 - Discussion started: 18 April 2017

Revised: 10 October 2017 - Accepted: 21 October 2017 - Published: 4 December 2017

\begin{abstract}
Paleogeographic reconstructions are important to understand Earth's tectonic evolution, past eustatic and regional sea level change, paleoclimate and ocean circulation, deep Earth resources and to constrain and interpret the dynamic topography predicted by mantle convection models. Global paleogeographic maps have been compiled and published, but they are generally presented as static maps with varying map projections, different time intervals represented by the maps and different plate motion models that underlie the paleogeographic reconstructions. This makes it difficult to convert the maps into a digital form and link them to alternative digital plate tectonic reconstructions. To address this limitation, we develop a workflow to restore global paleogeographic maps to their present-day coordinates and enable them to be linked to a different tectonic reconstruction. We use marine fossil collections from the Paleobiology Database to identify inconsistencies between their indicative paleoenvironments and published paleogeographic maps, and revise the locations of inferred paleo-coastlines that represent the estimated maximum transgression surfaces by resolving these inconsistencies. As a result, the consistency ratio between the paleogeography and the paleoenvironments indicated by the marine fossil collections is increased from an average of $75 \%$ to nearly full consistency (100\%). The paleogeography in the main regions of North America, South America, Europe and Africa is significantly revised, especially in the Late Carboniferous, Middle Permian, Triassic,
\end{abstract}

Jurassic, Late Cretaceous and most of the Cenozoic. The global flooded continental areas since the Early Devonian calculated from the revised paleogeography in this study are generally consistent with results derived from other paleoenvironment and paleo-lithofacies data and with the strontium isotope record in marine carbonates. We also estimate the terrestrial areal change over time associated with transferring reconstruction, filling gaps and modifying the paleogeographic geometries based on the paleobiology test. This indicates that the variation of the underlying plate reconstruction is the main factor that contributes to the terrestrial areal change, and the effect of revising paleogeographic geometries based on paleobiology is secondary.

\section{Introduction}

Paleogeography, describing the ancient distribution of highlands, lowlands, shallow seas and deep ocean basins, is widely used in a range of fields including paleoclimatology, plate tectonic reconstructions, paleobiogeography, resource exploration and geodynamics. Global deep-time paleogeographic compilations have been published (e.g., Blakey, 2008; Golonka et al., 2006; Ronov, et al., 1984, 1989; Scotese, 2001, 2004; Smith et al., 1994). However, they are generally presented as static paleogeographic snapshots with varying map projections and different time intervals represented by the maps, and are tied to different plate motion 
models. This makes it difficult to convert the maps into a digital format, link them to alternative digital plate tectonic reconstructions and update them when plate motion models are improved. It is therefore challenging to use paleogeographic maps to help constrain or interpret numerical models of mantle convection that predict long-wavelength topography (Gurnis et al., 1998; Spasojevic and Gurnis, 2012) based on different tectonic reconstructions, or as an input to models of past ocean and atmosphere circulation/climate (Goddéris et al., 2014; Golonka et al., 1994) and models of past erosion/sedimentation (Salles et al., 2017).

In order to address these issues, we develop a workflow to restore the ancient paleogeographic geometries back to their modern coordinates so that the geometries can be attached to a different plate motion model. This is the first step towards the construction of paleogeographic maps with flexible spatial and temporal resolutions that are more easily testable and expandable with the incorporation of new paleoenvironmental data sets (e.g., Wright et al., 2013). In this study, we use a set of global paleogeographic maps (Golonka et al., 2006) covering the entire Phanerozoic time period as the base paleogeographic model. Coastlines on these paleogeographic maps represent estimated maximum marine transgression surfaces (Kiessling et al., 2003). We first restore the global paleogeographic geometries of Golonka et al. (2006) to their present-day coordinates by reversing the sign of the rotation angle, and then reconstruct them to geological times using a different plate motion model of Matthews et al. (2016). We then use paleoenvironmental information from marine fossil collections from the Paleobiology Database to modify the inferred paleo-coastline locations and paleogeographic geometries. Next, we use the revised paleogeography to estimate the surface areas of global paleogeographic features including deep oceans, shallow marine environments, landmasses, mountains and ice sheets. In addition, we compare the global flooded continental areas since the Devonian calculated from the revised paleogeography with other results derived from other paleoenvironment and paleo-lithofacies maps (Ronov, 1994; Smith et al., 1994; Walker et al., 2002; Blakey, 2003, 2008; Golonka, 2007b, 2009, 2012) or from the strontium isotope record (van der Meer et al., 2017). We estimate the terrestrial areal change over time associated with transferring reconstruction, filling gaps and modifying the paleogeographic geometries based on consistency test. Finally, we test the marine fossil collection data set used in this study for fossil abundances over time using different timescales of the International Commission on Stratigraphy (ICS2016; Cohen et al., 2013, updated) and of Golonka (2000) and discuss the limitations of the workflow we develop in this study.

\section{Data and paleogeographic model}

The data used in this study are global paleogeographic maps and paleoenvironmental data for the last 402 million years
(Myr), which originate from the set of paleogeographic maps produced by Golonka et al. (2006) and the Paleobiology Database (PBDB, https://paleobiodb.org), respectively. The global paleogeographic compilation extending back to the Early Devonian of Golonka et al. (2006) is divided into 24 time-interval maps using the timescale of Golonka (2000) which is based on the original timescale of Sloss (1988; Table 1). Each map is a compilation of paleo-lithofacies and paleoenvironments for each geological time interval. These paleogeographic reconstructions illustrate the changing configuration of ice sheets, mountains, landmasses, shallow marine environments (inclusive of shallow seas and continental slopes) and deep oceans over the last $\sim 400 \mathrm{Myr}$.

The paleogeographic maps of Golonka et al. (2006) are constructed using a plate tectonic model available in the supplement of Golonka (2007a), where relative plate motions are described. In this rotation model, paleomagnetic data are used to constrain the paleolatitudinal positions of continents and rotation of plates, and hotspots, where applicable, are used as reference points to calculate paleolongtitudes (Golonka, 2007a). This rotation model is necessary to restore these paleogeographic geometries (Golonka et al., 2006) to their present-day coordinates so that they can be attached to a different plate motion model. The relative plate motions of Golonka $(2006,2007 a)$ are based on the reconstruction of Scotese $(1997,2004)$.

Here, we use a global plate kinematic model to reconstruct paleogeographies back in time from present-day locations. The global tectonic reconstruction of Matthews et al. (2016), with continuously closing plate boundaries from $410-0 \mathrm{Ma}$, is primarily constructed from a Mesozoic and Cenozoic plate model (230-0 Ma; Müller et al., 2016) and a Paleozoic model (410-250 Ma; Domeier and Torsvik, 2014). This model is a relative plate motion model that is ultimately tied to Earth's spin axis through a paleomagnetic reference frame for times before $70 \mathrm{Ma}$, and a moving hotspot reference frame for younger times (Matthews et al., 2016).

The PBDB is a compilation of global fossil data covering deep geological time. All fossil collections in the database contain detailed metadata, including on the time range (typically biostratigraphic age), present-day geographic coordinates, host lithology and paleoenvironment. Figure 1 represents distributions of the global fossil collections at presentday coordinates and shows their numbers since the Devonian. The recorded fossil collections are unevenly distributed both spatially and temporally, largely due to the differences in fossil preservation, the spatial sampling biases of fossil localities and the uneven entry of fossil data to the PBDB (Alroy, 2010). For this study, a total of 57854 fossil collections with temporal and paleoenvironmental assignments from 402 to $2 \mathrm{Ma}$ were downloaded from the database on 7 September 2016. 


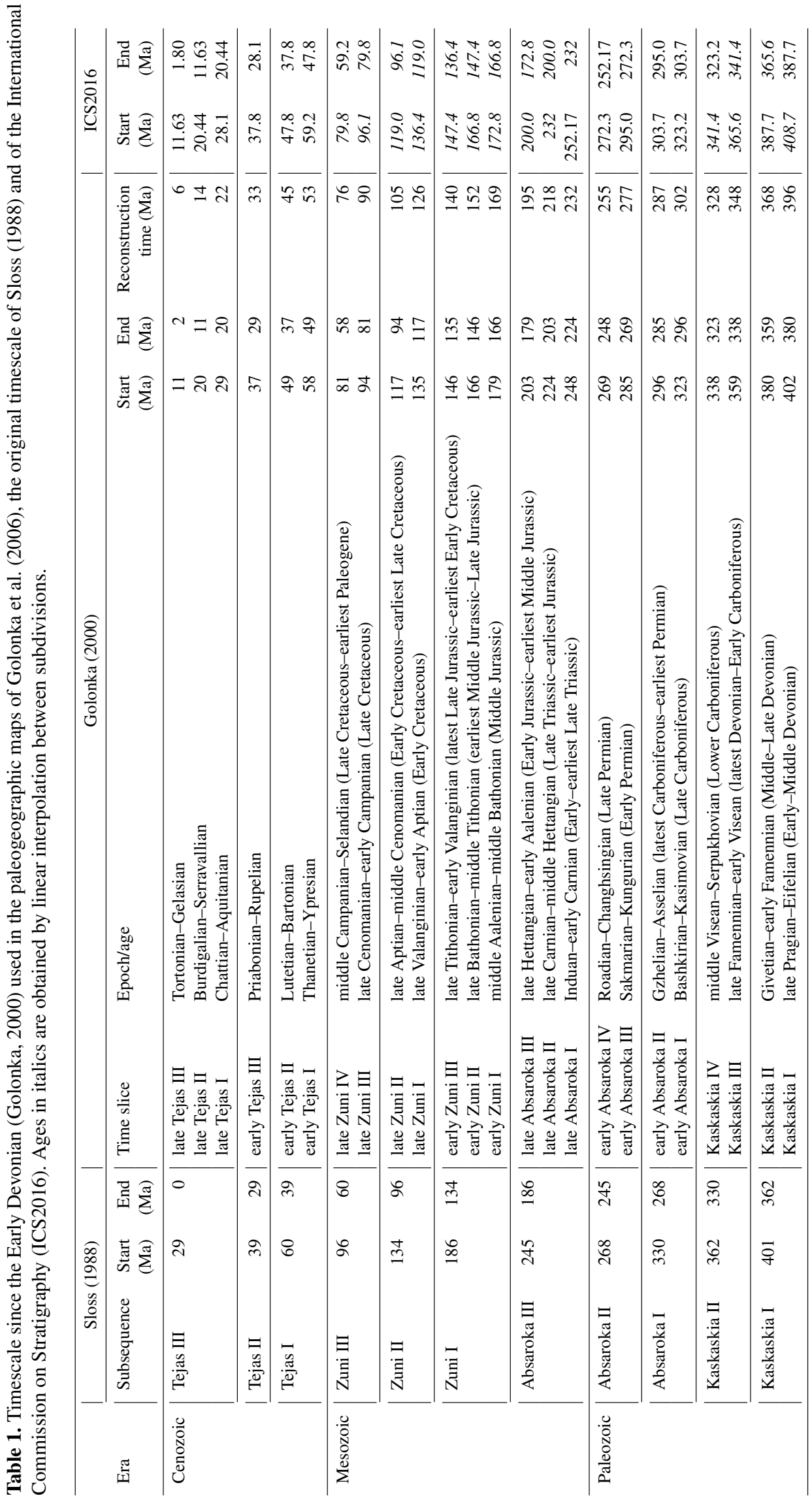



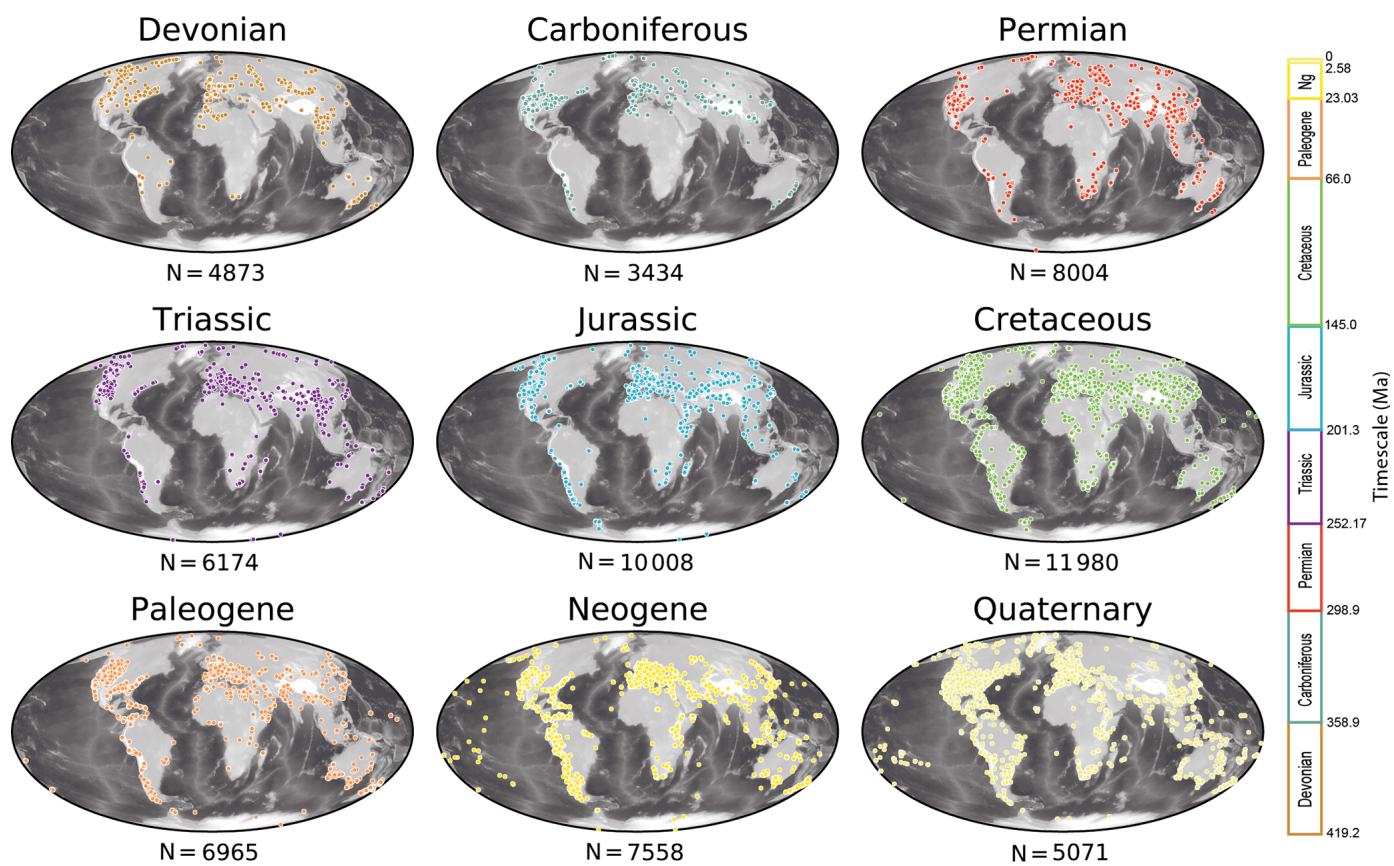

Figure 1. Global distributions and number of fossil collections since the Devonian. The greyscale background shows global present-day topography ETOPO1 (Amante and Eakins, 2009) with lighter shades corresponding to increasing elevation. Fossil collections from the PBDB are colored following the standard used by the International Commission on Stratigraphy.

\section{Methods}

The methodology can be divided into three main steps: (1) the original paleogeographic geometries are restored to present-day coordinates by applying the inverse of the rotations used to make the reconstruction, (2) these restored geometries are then rotated to new locations using the plate tectonic model of Matthews et al. (2016) and (3) the paleocoastline locations and paleogeographic geometries are adjusted using paleoenvironmental data from the PBDB. Figure 2 illustrates the generalized workflow that can be applied to a different paleogeography model. In order to represent the paleogeographic maps as digital geographic geometries, they are first georeferenced using the original projection and coordinate system (global Mollweide in Golonka et al., 2006), and then re-projected into the WGS84 geographic coordinate system. The resulting maps are then attached to the original rotation model using the open-source and cross-platform plate reconstruction software GPlates (http://gplates.org). Every plate is then assigned a unique plate ID that defines the rotation of the tectonic elements so that the paleogeographic geometries can be rotated back to their present-day coordinates (see example in Fig. 3a, b). We use present-day coastlines and terrane boundaries with the plate IDs of Golonka (2007a) as a reference to refine the rotations and ensure that the paleogeographic geometries are restored accurately to their present-day locations.

When the paleogeographic geometries in present-day coordinates are attached to a new reconstruction model, as

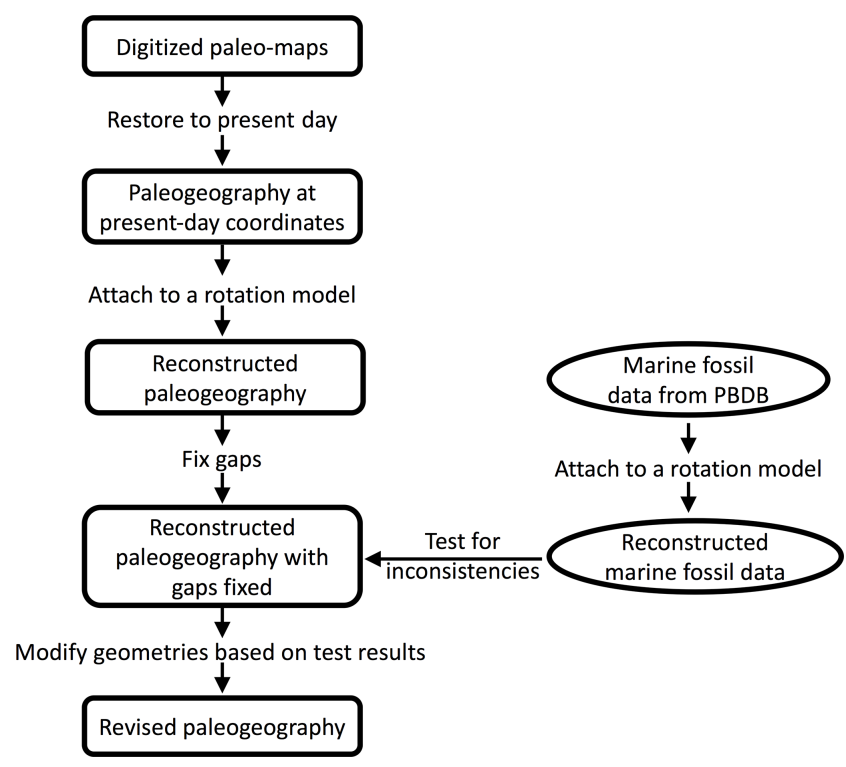

Figure 2. Workflow used to transfer a set of paleogeographic geometries from one reconstruction to another, followed by revision using paleoenvironmental information indicated by marine fossil collections from the Paleobiology Database (PBDB).

Matthews et al. (2016) used in this study, the resulting paleogeographies result in gaps (Fig. 3c, pink) and overlaps between neighboring polygons, when compared to the original reconstruction (Fig. 3a). These gaps and overlaps essentially 


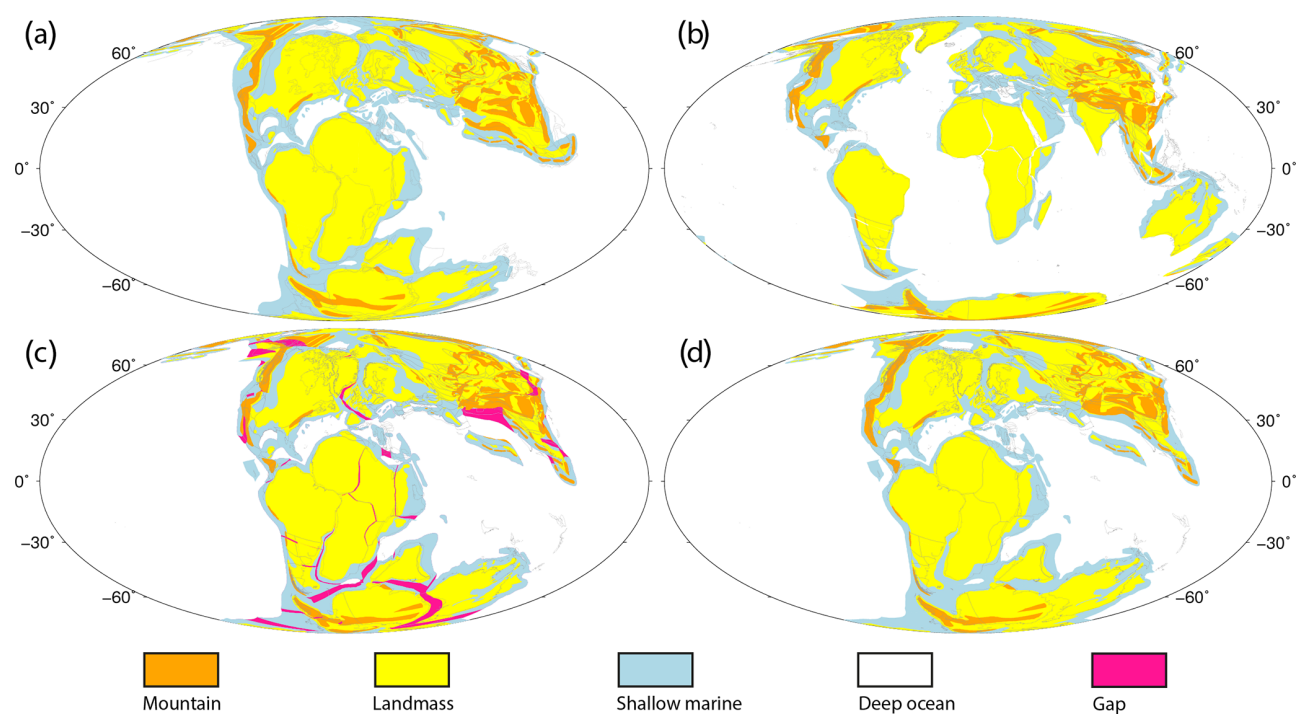

Figure 3. (a) Original global paleogeographic map from Golonka et al. (2006) at $126 \mathrm{Ma}$. (b) Global paleogeographic geometries at $126 \mathrm{Ma}$ in present-day coordinates. (c) Global paleogeography at 126 Ma reconstructed using the plate motion model of Matthews et al. (2016). Gaps are highlighted in pink. (d) Global paleogeography at 126 Ma reconstructed using the reconstruction of Matthews et al. (2016) with gaps fixed by filling with adjacent paleoenvironment attributes. Grey lines indicate reconstructed present-day coastlines and terrane boundaries. Mollweide projection with $0^{\circ} \mathrm{E}$ central meridian.

Table 2. Lookup table to classify fossil data indicating different paleoenvironments into marine or terrestrial settings and their corresponding paleogeographic types presented in Golonka et al. (2006). Terrestrial fossil paleoenvironments correspond to paleogeographic features of landmasses, mountains or ice sheets and marine fossil paleoenvironments to shallow marine environments or deep oceans.

\begin{tabular}{|c|c|c|c|c|c|}
\hline \multicolumn{3}{|c|}{ Marine } & \multicolumn{3}{|c|}{ Terrestrial/transitional zone } \\
\hline Paleogeography & \multicolumn{2}{|c|}{ Fossil paleoenvironments } & Paleogeography & \multicolumn{2}{|c|}{ Fossil paleoenvironments } \\
\hline \multirow{18}{*}{ 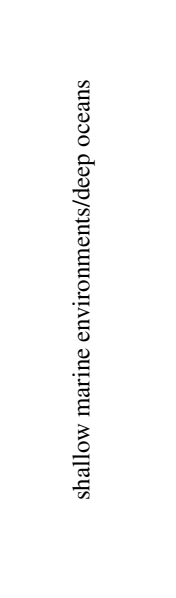 } & marine indet. & slope & \multirow{17}{*}{ 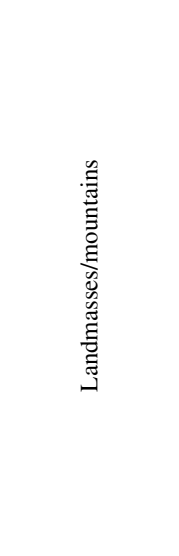 } & terrestrial indet. & pond \\
\hline & carbonate indet. & basinal (carbonate) & & fluvial indet. & crater lake \\
\hline & peritidal & basinal (siliceous) & & alluvial fan & lacustrine delta plain \\
\hline & shallow subtidal indet. & marginal marine indet. & & channel lag & lacustrine interdistributary bay \\
\hline & open shallow subtidal & coastal indet. & & coarse channel fill & lacustrine delta front \\
\hline & lagoonal/restricted shallow subtidal & estuary/bay & & fine channel fill & lacustrine prodelta \\
\hline & sand shoal & lagoonal & & channel & lacustrine deltaic indet. \\
\hline & reef, buildup or bioherm & paralic indet. & & wet floodplain & lacustrine indet. \\
\hline & $\begin{array}{l}\text { peri-reef or sub-reef } \\
\text { intra-shelf/intraplatform reef }\end{array}$ & $\begin{array}{l}\text { interdistributary bay } \\
\text { delta front }\end{array}$ & & dry floodplain & $\begin{array}{l}\text { dune } \\
\text { inter-dune }\end{array}$ \\
\hline & platform/shelf-margin reef & prodelta & & crevasse splay & loess \\
\hline & slope/ramp reef & deltaic indet. & & levee & eolian indet. \\
\hline & basin reef & foreshore & & mire/swamp & cave \\
\hline & deep subtidal ramp & shore face & & fluvial-lacustrine indet. & fissure fill \\
\hline & deep subtidal shelf & transition zone/lower shore face & & delta plain & sinkhole \\
\hline & deep subtidal indet. & offshore & & fluvial-deltaic indet. & karst indet. \\
\hline & offshore ramp & submarine fan & & lacustrine - large & \\
\hline & offshore shelf & basinal (siliciclastic) & & lacustrine - small & spring \\
\hline & offshore indet. & deep-water indet. & ice sheets & \multicolumn{2}{|l|}{ glacial } \\
\hline
\end{tabular}

arise from the differences in the reconstructions described in Matthews et al. (2016) and Golonka et al. (2006). The reconstruction of Golonka et al. (2006) has a tighter fit of the major continents within Pangea prior to the supercontinent breakup. In addition, this reconstruction contains a different plate motion history and block boundary definitions in regions of complex continental deformation, for example along active continental margins (e.g., Himalayas, western North America; Fig. 3c).

The gaps and overlaps cause changes in the total terrestrial or oceanic paleogeographic areas at different time intervals, becoming larger or smaller, when compared with the original paleogeographic maps (Golonka et al., 2006). The gaps can be fixed by interactively extending the outlines of the polygons in a GIS platform to make the plates connect as in 
the original paleogeographic maps (Fig. 3a, c, d). Changes in the extent of total terrestrial or oceanic area of the paleogeographies with filled gaps are compared with the original paleogeographies in Fig. 3d (Golonka et al., 2006).

Once the gaps are filled, the reconstructed paleogeographic features are compared with the paleoenvironments indicated by the marine fossil collections from the PBDB. These comparisons aim to identify the differences between the mapped paleogeography and the marine fossil collection environments in order to revise the paleo-coastline locations and paleogeographic geometries. Fossil collections belonging to each time interval (Table 1; Golonka, 2000) are first extracted from the data set downloaded from the PBDB. Only the fossil collections with temporal ranges lying entirely within the corresponding time intervals are selected, as opposed to including the fossil collections that have larger temporal ranges. Fossil collections with temporal ranges crossing any time-interval boundary are not taken into consideration. As a result, a minimum number of fossil collections are selected for each time interval. The selected fossil collections are classified into either the terrestrial or marine setting category, according to a lookup table (Table 2).

Marine fossil collections are then attached to the plate motion model of Matthews et al. (2016) so they can be reconstructed at each time interval. Subsequently, a point-inpolygon test is used to determine whether or not the indicated marine fossil collection is within the appropriate marine paleogeographic polygon. The results of these tests are discussed in the following section.

In the next step, we modify the paleo-coastline locations and paleogeographic geometries based on the test (Figs. 4, 5 and Supplement). Modifications are made according to the following rules. (1) Marine fossil collections from the PBDB are presumed to be well dated, constrained geographically, not reworked and representative of their broader paleoenvironments. Their indicative environments are assumed to be correct. (2) Only marine fossil collections within $500 \mathrm{~km}$ of the nearest paleo-coastlines are taken into account as most marine fossil collections used in this study are located within $500 \mathrm{~km}$ from the paleo-coastlines (see Fig. S1 in the Supplement). (3) The paleo-coastlines and paleogeographic geometries are modified until they are consistent with the marine fossil collection environments and at the same time remain about $30 \mathrm{~km}$ distance from the fossil points used (Fig. 5c, f, 1). (4) The adjacent paleo-coastlines are accordingly adjusted and smoothed (Figs. 4, 5). (5) The modified area (Fig. 5b, e, k, blue) resulting from shifting the coastline is filled using the shallow marine environment. These rules are designed to maximize the use of the paleoenvironmental information obtained from the marine fossil collections to improve the coastline locations and paleogeography while attempting to minimize spurious modifications.

However, in some rare cases, outlier marine fossil data may be a deceptive recorder of paleogeography. For instance, Wichura et al. (2015) discussed the discovery of a $\sim 17 \mathrm{Myr}$
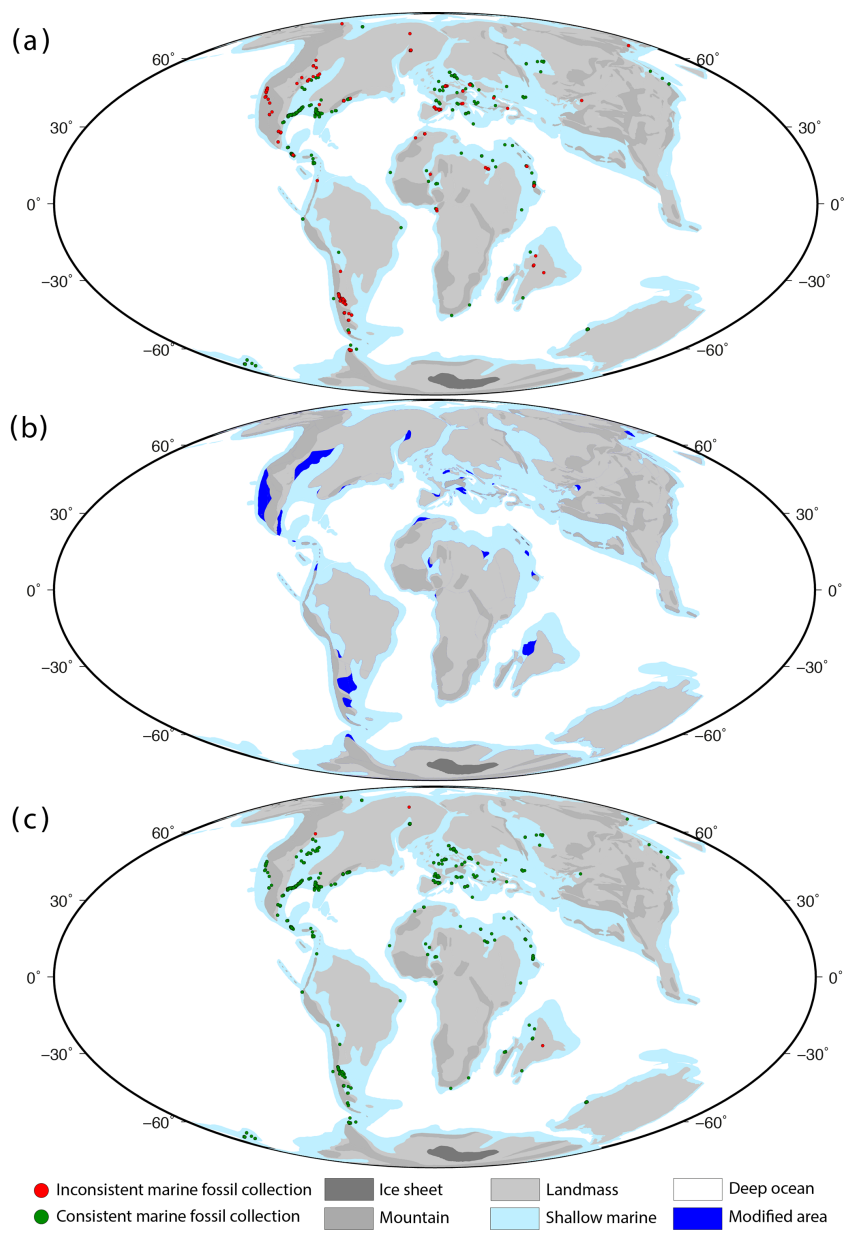

Figure 4. (a) Test between the global paleogeography at $76 \mathrm{Ma}$ reconstructed using the plate motion model of Matthews et al. (2016) with gaps fixed and the paleoenvironments indicated by the marine fossil collections from the PBDB. (b) Area modified (blue) to resolve the test inconsistencies. (c) Test between the revised paleogeography at $76 \mathrm{Ma}$ and the same marine fossil collections. Mollweide projection with $0^{\circ} \mathrm{E}$ central meridian.

old beaked whale fossil $740 \mathrm{~km}$ inland from the present-day coastline of the Indian Ocean in east Africa. The authors found evidence to suggest that this whale could have traveled inland from the Indian Ocean along an eastward-directed fluvial (terrestrial) drainage system and was stranded there, rather than representing a marine setting that would be implied under our assumptions. Therefore, theoretically, when using the fossil collections to improve paleogeography, additional concerns about living habits of fossils and associated geological settings should be taken into account. In this study, we have removed this misleading fossil whale from the data set. Such instances of deceptive fossil data are a potential limitation within our workflow, which we seek to minimize by excluding inconsistent fossils more than $500 \mathrm{~km}$ away from previously interpreted paleo-coastlines described above. 


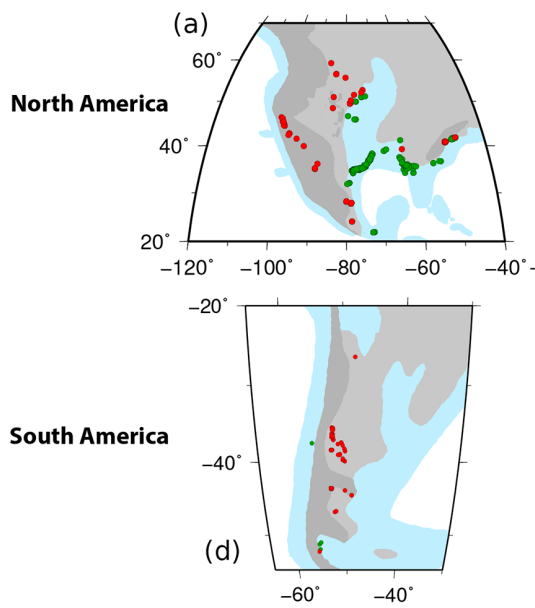

(b)
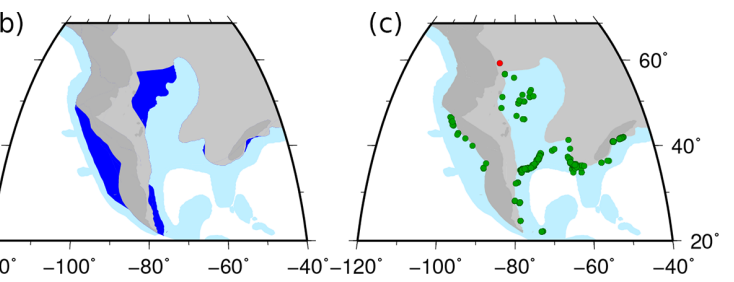

(e)

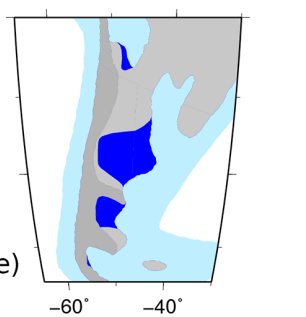

(f)
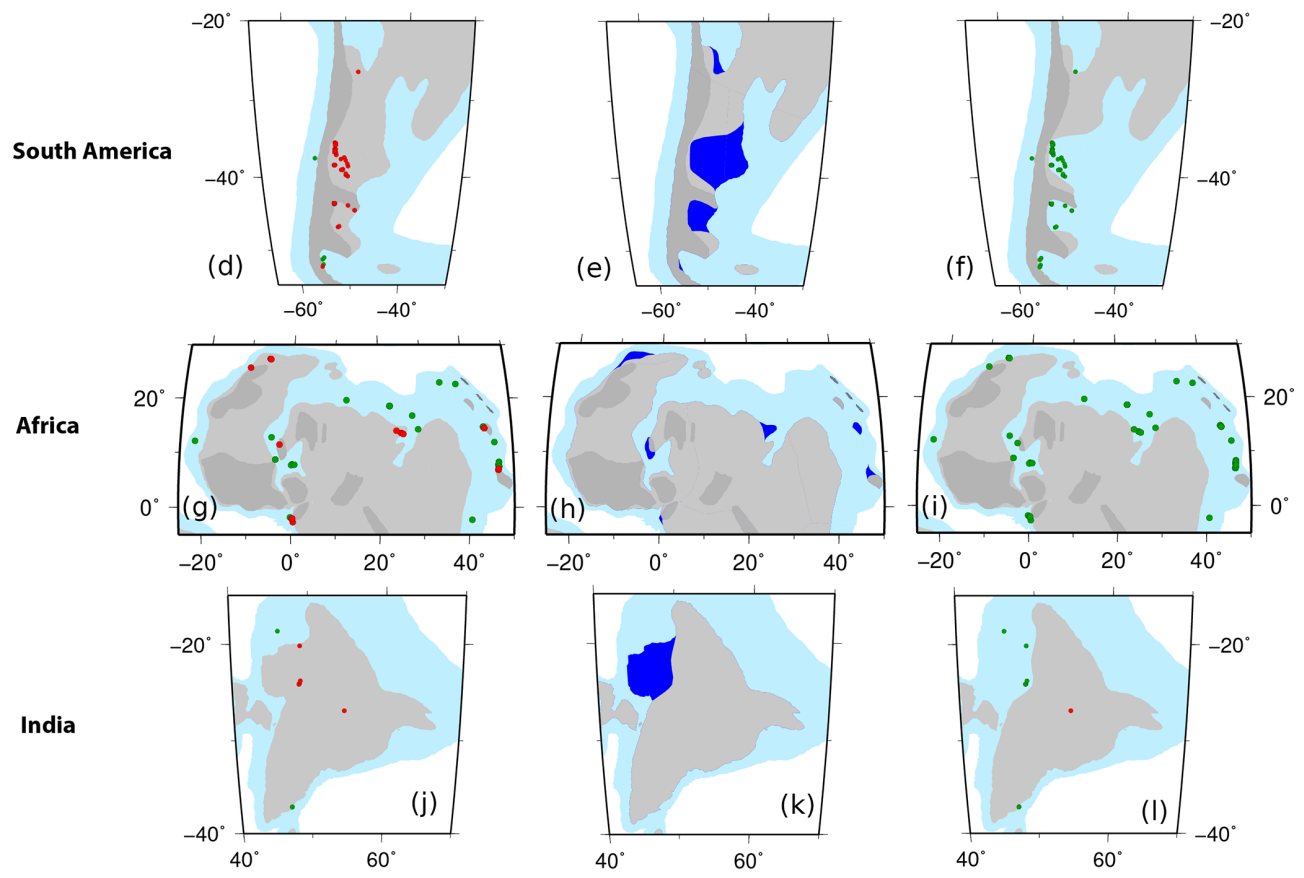

Inconsistent marine fossil collection

Consistent marine fossil collection
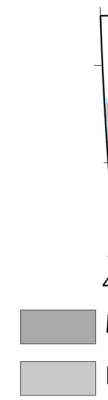
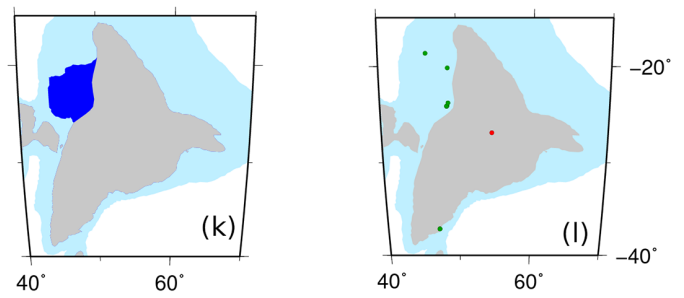

Mountain

Landmass

Shallow marine

Modified area

Deep ocean

Figure 5. Test between unrevised and revised paleogeography at $76 \mathrm{Ma}$, respectively, and paleoenvironments indicated by the marine fossil collections from the PBDB, and revision of the paleo-coastlines and paleogeographic geometries based on the test results, for southern North America (a, b, c), southern South America (d, e, f), northern Africa $(\mathbf{g}, \mathbf{h}, \mathbf{i})$ and India $(\mathbf{j}, \mathbf{k}, \mathbf{l})$. Regional Mollweide projection.

\section{Results}

\subsection{Paleoenvironmental tests}

Global reconstructed paleogeographic maps from 402 to $2 \mathrm{Ma}$ are tested against paleoenvironments indicated by the marine fossil collections that are reconstructed in the same rotation model (Matthews et al., 2016). The consistency ratio is defined by the marine fossil collections within shallow marine or deep ocean paleogeographic polygons as a percentage of all marine fossil collections at the time interval, and in contrast, the inconsistency ratio is defined by the marine fossil collections not within shallow marine or deep ocean paleogeography as a percentage of all marine fossil collections. Heine et al. (2015) used a similar metric to evaluate global paleo-coastline models since the Cretaceous.

The inconsistent marine fossil collections are used to modify coastlines and paleogeographic geometries according to the rules outlined in the Methods section. The consistency ratios of marine fossil collections during 402-2 Ma are all over $55 \%$, with an average of $75 \%$ (Fig. 6a, shaded area) although with large fluctuations over time (Fig. 6). This indicates that the paleogeography of Golonka et al. (2006) has relatively high consistency with the fossil records. However, 52 fossil collections over all time intervals cannot be resolved as they are over $500 \mathrm{~km}$ distant from the nearest coastline (for example, red points in Fig. 5c, 1). Therefore, in some cases, the paleogeography cannot be fully reconciled with the paleobiology (see Supplement). The results since the Cretaceous are similar to that of Heine et al. (2015).

The sums of marine fossil collections change significantly over time (Fig. 6b); for example, there are more than 4000 in total within 269-248 Ma but only 20 during 37-29 Ma. These variations are due to the spatiotemporal sampling bias and incompleteness of the fossil record (Benton et al., 2000; Benson and Upchurch, 2013; Smith et al., 2012; Valentine et al., 2006; Wright et al., 2013), biota extinction and recovery (Hallam and Wignall, 1997; Hart, 1996), the uneven entry of 


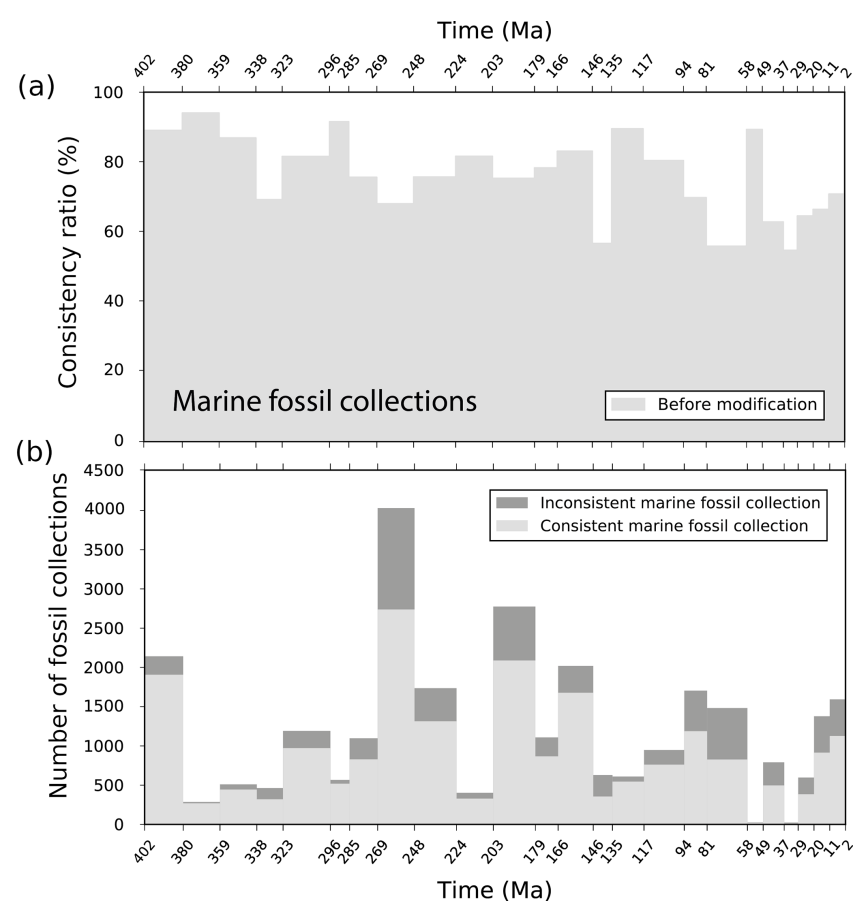

Figure 6. (a) Consistency ratios between global paleogeography with gap filled, but before PBDB test for the period 402-2 Ma, reconstructed using the plate motion model of Matthews et al. (2016) and the paleoenvironments indicated by the marine fossil collections from the PBDB. (b) Numbers of consistent (light grey) and inconsistent (dark grey) marine fossil collections used in the tests for each time interval from 402 to $2 \mathrm{Ma}$.

fossil data to the PBDB (Alroy, 2010) and our temporal selection criterion. In addition, the differences in the duration of geological time subdivisions lead to some time intervals having shorter time spans that contain fewer fossil records, which we discuss in a later section. As for the time intervals during which fossil data are scarce, the fossil collections are of limited use in improving paleogeography. However, additional records in the future will increase the usefulness of the PBDB in such instances.

\subsection{Revised global reconstructed paleogeography}

Based on the PBDB test results at all the time intervals, we can revise the inferred paleo-coastlines and paleogeographic geometries using the approach described in the Methods section. As a result, the revised paleo-coastlines and paleogeographies are significantly improved, mainly in the regions of North America, South America, Europe and Africa during the Late Carboniferous, Middle Permian, Triassic, Jurassic, Late Cretaceous and most of Cenozoic (Figs. 4, 5, 6 and Supplement). The resulting improved global paleogeographic maps since the Devonian are presented in Fig. 7. They provide improved paleo-coastlines that are important to constrain past changes in sea level and long-wavelength dynamic topography.
We subsequently calculate the area covered by each paleogeographic feature as a percentage of Earth's total surface area at each time interval from 402 to $2 \mathrm{Ma}$ (Fig. 8), using the HEALPix pixelization method that results in equal sampling of data on a sphere (Górski et al., 2005) and therefore equal sampling of surface areas. This method effectively excludes the effect of overlaps between paleogeographic geometries.

As a result, the areas of landmass, mountain and ice sheet generally indicate increasing trends, while shallow marine and deep ocean areas show decreasing trends through geological time (Fig. 8). Overall, the computed areas increase in the following order: ice sheet (average $1.0 \%$ of Earth surface), mountain belts $(3.4 \%)$, shallow marine $(14.3 \%)$, landmass $(21.3 \%)$ and deep ocean $(60.1 \%)$. Only during the time interval of 323-296 Ma are landmass and shallow marine areas nearly equal at about $14.0 \%$, and only during 359-285 Ma do ice sheet areas exceed mountain areas, but ice sheets only exist during 380-285, 81-58 and 37$2 \mathrm{Ma}$. With Pangea formation during the latest Carboniferous or the Early Permian and breakup initiation in the Early Jurassic (Blakey, 2003; Domeier et al., 2012; Lenardic, 2016; Stampfli et al., 2013; Vai, 2003; Veevers, 2004; Yeh and Shellnutt, 2016), these paleogeographic feature areas significantly change over time (Fig. 8). During 323-296 Ma (Late Carboniferous-earliest Permian), the landmass extent reaches its smallest area (13.6\%) and subsequently undergoes a rapid increase until peaking at $26.6 \%$ between 224 and $203 \mathrm{Ma}$ (Late Triassic). In contrast, ice sheets reach their largest area (7.2\%) between 323 and $296 \mathrm{Ma}$. In the Early Jurassic of Pangea breakup, landmass area rapidly decreases from $26.6 \%$ between 224 and 203 Ma to $23.5 \%$ between 203 and $179 \mathrm{Ma}$, but shallow marine area increases by $3.7 \%$.

\section{Discussions}

\subsection{Global flooded continental areas}

We estimate the global flooded continental areas since the Early Devonian from the revised paleogeography in this study (Fig. 9, pink solid line) and from the original paleogeographic maps of Golonka et al. (2006; Fig. 9, grey solid line). Both sets of results are similar, with a decrease during Pangea amalgamation from the Late Devonian until the Late Carboniferous, increase from the Early Jurassic with the breakup of Pangea until the Late Cretaceous and then a decrease again until the Pleistocene. We compare the two curves (pink solid line, grey solid line; Fig. 9) to the results of other studies (Fig. 9; Ronov, 1994; Smith et al., 1994; Walker et al., 2002; Blakey, 2003, 2008; Golonka, 2007b, 2009, 2012) derived from independent paleoenvironment and paleo-lithofacies data. The results are generally consistent, except for the periods 338-269 Ma and 248-203 Ma, during which the flooded continental areas for this study and Golonka et al. (2006) are smaller, reflecting smaller extent 

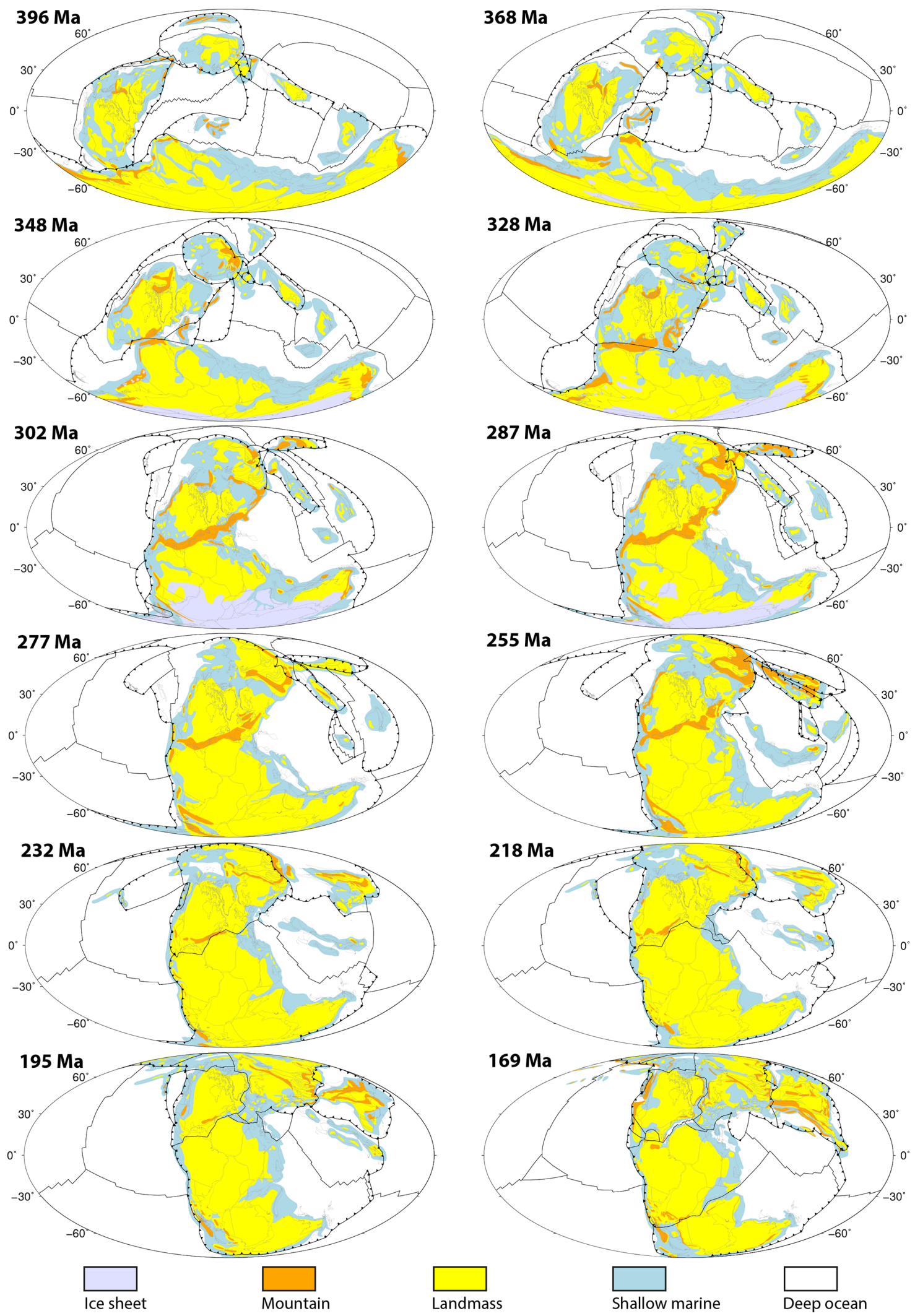

Figure 7. Global paleogeography from 402 to 2 Ma reconstructed using the plate motion model of Matthews et al. (2016) and revised using paleoenvironmental data from the PBDB. Black dotted lines indicate subduction zones, and other black lines denote mid-ocean ridges and transforms. Grey outlines delineate reconstructed present-day coastlines and terranes. Mollweide projection with $0^{\circ} \mathrm{E}$ central meridian. 

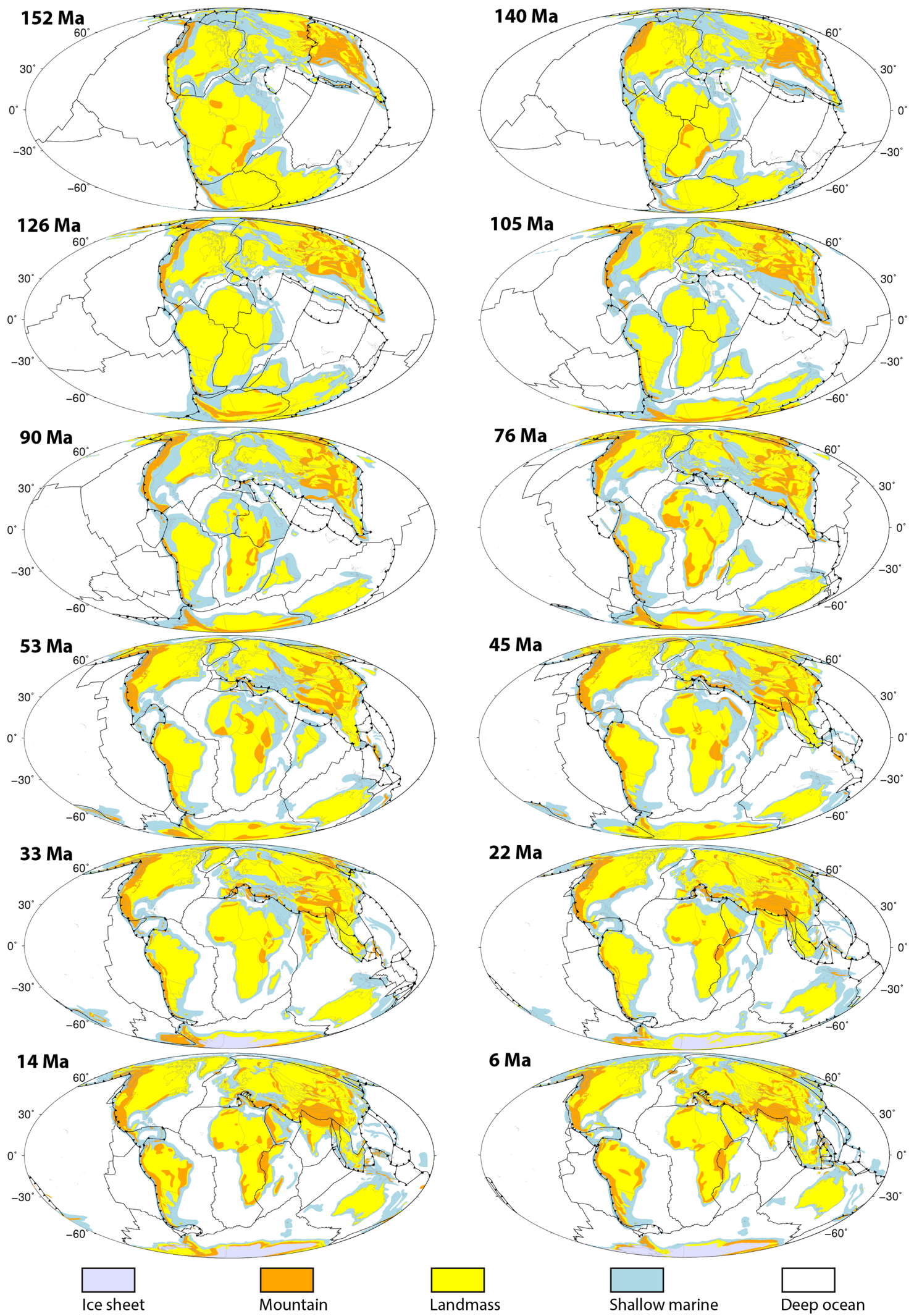

Figure 7. (continued) 


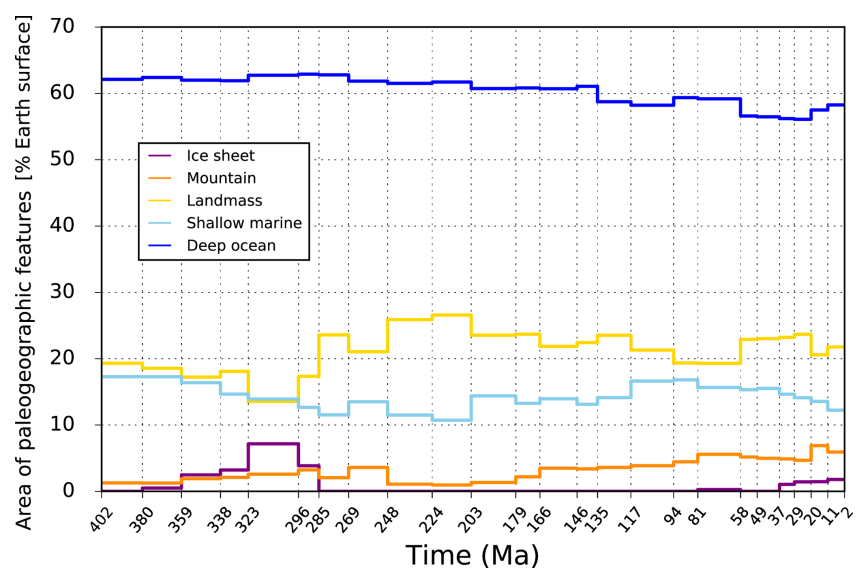

Figure 8. Global paleogeographic feature areas as percentages of Earth's total surface area estimated from the revised paleogeographic maps from $402 \mathrm{Ma}$ to $2 \mathrm{Ma}$.

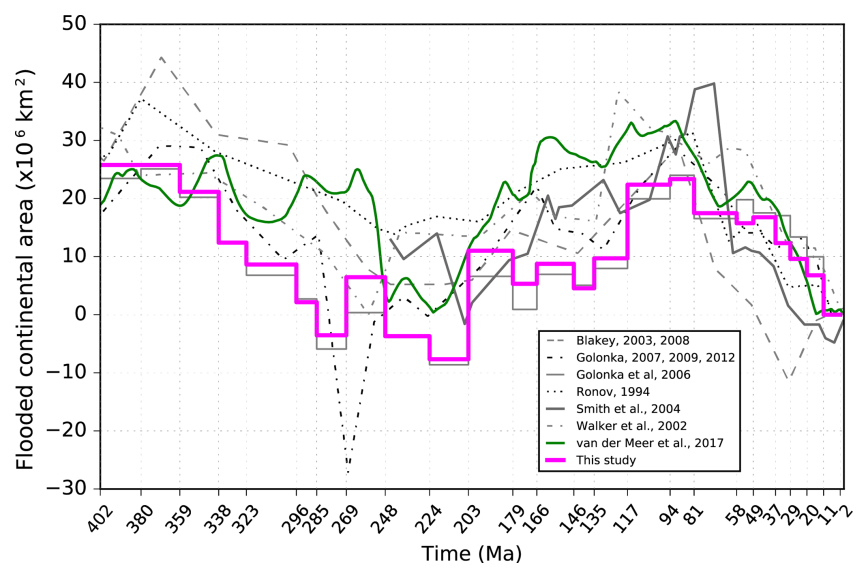

Figure 9. Global flooded continental area since the Early Devonian from the original paleogeographic maps of Golonka et al. (2006; grey solid line) and from the revised paleogeography in this study (pink line). Results for Blakey (2003, 2008), Golonka (2007b, 2009, 2012), Ronov (1994), Smith et al. (2004) and Walker et al. (2002) are as in van der Meer et al. (2017). The van der Meer et al. (2017) curve (green line) is derived from the strontium isotope record of marine carbonates.

of transgression in these times. Van der Meer et al. (2017, green line in Fig. 9) derived sea level and continental flooding from the strontium isotope record of marine carbonates. These results are generally consistent with the estimates from paleoenvironment and paleo-lithofacies data, except during the Permian and the Late Jurassic-early Cretaceous, during which van der Meer et al. (2017) predict larger extent of flooding than others (Fig. 9). This could indicate that the evolution of ${ }^{87} \mathrm{Sr} /{ }^{86} \mathrm{Sr}$ reflects variations in the composition of emergent continental crust (Bataille et al., 2017; Flament et al., 2013) as well as global weathering rates (e.g., Flament et al., 2013; Vérard et al., 2015; van der Meer et al., 2017).

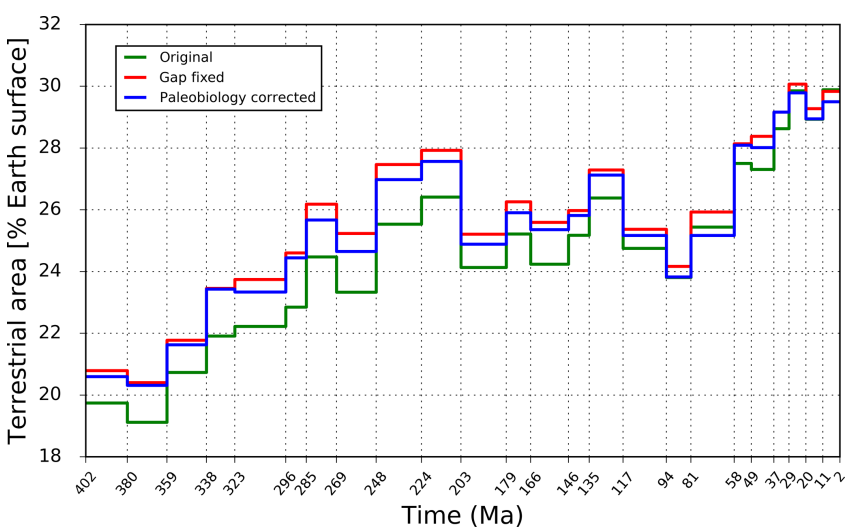

Figure 10. Terrestrial areal change due to filling gaps and modifying the paleo-coastlines and paleogeographic geometries over time. Green: based on the original paleogeographic maps of Golonka et al. (2006); red: based on paleogeography reconstructed using a different plate motion model of Matthews et al. (2016) and gaps filled; blue: based on paleogeography with gaps fixed and revised using the paleoenvironments indicated by marine fossil collections from the PBDB.

\subsection{Terrestrial areal change associated with transferring reconstruction, filling gaps and revising paleogeography}

We estimate the terrestrial areas, including ice sheets, mountains and landmasses, as percentages of Earth's surface area, from the original paleogeography of Golonka et al. (2006; Fig. 10, green), from the paleogeography reconstructed using a different plate motion model of Matthews et al. (2016) and gaps filled (Fig. 10, red) and from the paleogeography with gaps fixed and revised using the paleoenvironmental information indicated by marine fossil collections from the PBDB (Fig. 10, blue). These three curves are similar and generally indicate a reverse changing trend to the flooded continental areal curves over time (Fig. 9), as expected. We also calculate the areas of the terrestrial paleogeographic geometries after transferring the reconstruction but before filling gaps and the results are nearly identical to the original terrestrial paleogeographic areas of Golonka et al. (2006). This is because the reconstruction of Golonka et al. (2006) has a tighter fit of the major continents within Pangea prior to the supercontinent breakup than the reconstruction of Matthews et al. (2016), so that transferring the paleogeographic geometries mainly produces gaps rather than overlaps. Comparing between the three curves (Fig. 10), filling gaps results in a larger terrestrial areal change than revising paleogeographic geometries based on PBDB test. Therefore, variation of the underlying plate reconstruction is the main factor that contributes to the terrestrial areal change (Fig. 10, red and green), and the effect of revising paleogeographic geometries based on paleobiology is secondary (Fig. 10, blue). 


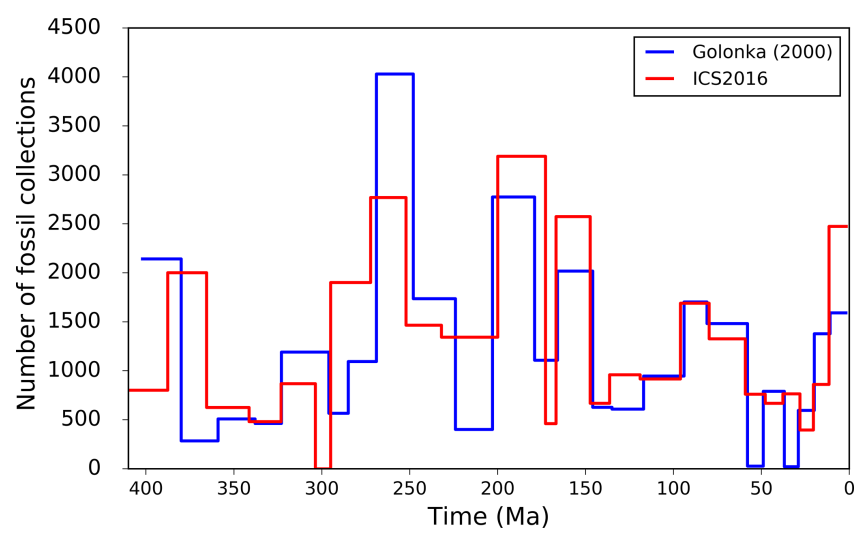

Figure 11. Fossil abundance test on the marine fossil collection data set used in this study with two different timescales: Golonka (2000) and ICS2016 (Table 1).

\subsection{Marine fossil collection abundances in two different timescales}

We test the marine fossil collection data set used in this study for fossil abundances over time with two different timescales: ICS2016 and Golonka (2000; Table 1). The results indicate the abundances of the data set in the two timescales are significantly different in most time intervals (Fig. 11). Generally, shorter time spans contain fewer data; for instance, there are about 400 marine fossil collections between 224 and $203 \mathrm{Ma}$ using the Golonka (2000) timescale (Fig. 11, red), while there are over 1300 collections during 232-200 Ma using the ICS2016 timescale (Fig. 11, blue). In addition, the difference of the start age and end age of the time interval could remarkably affect the fossil abundance, so that there are over 2000 marine fossil collections between 387.7 and $365.6 \mathrm{Ma}$ in ICS2016 but fewer than 300 collections between 380 and 359 Ma using the Golonka (2000) timescale. As a result, the timescale applied to the paleobiology could significantly affect the fossil collection abundance being assigned to paleogeographic time intervals.

\subsection{Limitations of the workflow}

The workflow we develop in this study illustrates transferring paleogeographic geometries from one plate motion model to another and then using paleoenvironmental information indicated by marine fossil collections from the PBDB to improve the paleo-coastline locations and paleogeographic geometries. However, the methodology still has some limitations. Transferring paleogeographic geometries to a different reconstruction inevitably results in gaps and/or overlaps, which can only be addressed using presently laborious methods. In addition, revising the coastlines and paleogeographic geometries based on the PBDB test is also currently achieved manually, and could be automated in the future.
Paleogeographic maps such as those considered here typically represent discrete time periods of many millions of years, whereas global plate motion models, even though also based on tectonic stages, provide a somewhat more continuous description of evolving plate configurations. A remaining question is how to provide a continuous representation of paleogeographic change that combines continuous plate motion models with paleogeographic maps that do not explicitly capture changes at the same temporal resolution. In addition, it is currently difficult to apply a timescale to the raw paleobiology data from the PBDB that are currently not tied to any timescale. The paleoenvironmental data used here have variable temporal resolutions, but the paleo-coastlines representing maximum transgressions are presented in a location at specific times. However, due to the inaccessibility of the original data that were used to build the paleogeographic maps, we are not in a position to estimate the temporal resolution of the original coastlines and paleogeographic maps.

The PBDB is a widely used resource (e.g., Wright et al., 2013; Finnegan et al., 2015; Heim et al., 2015; Mannion et al., 2015; Nicolson et al., 2015; Fischer et al., 2016; Tennant et al., 2016; Close et al., 2017; Zaffos et al., 2017), yet, the spatial coverage of data is still highly heterogeneous, with relatively few data points across large areas of the globe for some time periods. Hence, it is important to combine it with other geological data, such as stratigraphic data from StratDB Database (http://sil.usask.ca) and Macrostrat Database (https://macrostrat.org/) and other sources of paleoenvironment and paleo-lithofacies data, to further constrain the paleogeographic reconstructions.

\section{Conclusions}

Our study highlights the flexibility of digital paleogeographic models linked to plate tectonic reconstructions in order to better understand the interplay of continental growth and eustasy, with wider implications for understanding Earth's paleotopography, ocean circulation and the role of mantle convection in shaping long-wavelength topography. We present a workflow that enables the construction of paleogeographic maps with variable spatial and temporal resolutions, while also becoming more testable and expandable with the incorporation of new paleoenvironmental data sets.

We develop an approach to revise the paleo-coastline locations and paleogeographic geometries using paleoenvironmental information indicated by the marine fossil collections from the PBDB. Using this approach, the consistency ratio between the paleogeography and the paleobiology records since the Devonian is increased from an average $75 \%$ to nearly full consistency. The paleogeography in the main regions of North America, South America, Europe and Africa is significantly improved, especially in the Late Carboniferous, Middle Permian, Triassic, Jurassic, Late Cretaceous and most portions of the Cenozoic. The flooded continental ar- 
eas since the Late Devonian inferred from the revised global paleogeography in this study are generally consistent with the results derived from other paleoenvironment and paleolithofacies data or from the strontium isotope record in marine carbonates.

Comparing the terrestrial areal change over time associated with transferring the reconstruction and filling gaps, and revising paleogeographic geometries using the paleoenvironmental data from the PBDB, indicates that reconstruction difference is a main factor in paleogeographic areal change when comparing with the original maps, and revising paleogeographic geometries based on PBDB test is secondary.

\section{Information about the supplement}

We provide two sets of digital global paleogeographic maps during 402-2 Ma: (1) the paleogeography reconstructed using the plate motion model of Matthews et al. (2016) and revised using paleoenvironmental information indicated by the marine fossil collections from the PBDB and (2) the original paleogeography of Golonka et al. (2006). We also provide the original rotation file of Golonka et al. (2006), a set of paleogeographic maps illustrating the PBDB test and revision of paleo-coastlines and paleogeographic geometries, a set of GeoTiff files of all revised paleogeographic maps, paleobiology data in shapefile used in this study separated into two sets of consistent marine fossil collections and inconsistent marine fossil collections, an animation for the revised global paleogeographic maps, and a README file outlined the workflow of this study.

\section{The Supplement related to this article is available online at https://doi.org/10.5194/bg-14-5425-2017-supplement.}

Data availability. No data sets were used in this article.

Competing interests. The authors declare that they have no conflict of interest.

Acknowledgements. This work was supported by Australian Research Council grants IH130200012 (RDM, SZ), DE160101020 (NF) and SIEF RP 04-174 (SW). W. Cao was also supported by a University of Sydney International Scholarship (USydIS). We thank Julia Sheehan and Logan Yeo for digitizing these paleogeographic maps, and John Cannon and Michael Chin for help with GPlates and pyGPlates. We sincerely thank Shanan Peters and three anonymous reviewers for their constructive reviews and suggestions. We thank Natascha Töpfer for editorial support and Tina Treude for editing the manuscript. We are also thankful for the entire PBDB team and all PBDB data contributors. This is Paleobiology Database Publication 296.
Edited by: Tina Treude

Reviewed by: Shanan Peters and three anonymous referees

\section{References}

Amante, C. and Eakins, B. W.: ETOPO1 1 arc-minute global relief model: Procedures, data sources and analysis, NOAA Technical Memorandum NESDIS NGDC-24, National Geophysical Data Center, National Oceanic and Atmospheric Administration, 19 pp., 2009.

Alroy, J.: Geographical, environmental and intrinsic biotic controls on Phanerozoic marine diversification, Palaeontology, 53, 12111235, 2010.

Bataille, C. P., Willis, A., Yang, X., and Liu, X. M.: Continental igneous rock composition: A major control of past global chemical weathering, Science Advances, 3, 1-16, 2017.

Benson, R. B. J. and Upchurch, P.: Diversity trends in the establishment of terrestrial vertebrate eco-systems: interactions between spatial and temporal sampling biases, Geology, 41, 43-46, 2013.

Benton, M. J., Wills, M. A., and Hitchin, R.: Quality of the fossil record through time, Nature, 403, 534-537, 2000.

Blakey, R. C.: Carboniferous Permian global paleogeography of the assembly of Pangaea, in: Fifteenth International Congress on Carboniferous and Permian Stratigraphy, edited by: Wong, T. E., Royal Netherlands Academy of Arts and Sciences, Utrecht, the Netherlands, 443-465, 2003.

Blakey, R. C.: Gondwana paleogeography from assembly to breakup-A 500 m.y. odyssey, in: Resolving the Late Paleozoic Ice Age in Time and Space, edited by: Christopher R. Fielding, C. R., Frank, T. D., and Isbell, J. L., Geol. S. Am. S., 441, 1-28, https://doi.org/10.1130/2008.2441(01), 2008.

Close, R. A., Benson, R. B. J., Upchurch, P., and Butler, R. J.: Controlling for the species-area effect supports constrained long-term Mesozoic terrestrial vertebrate diversification, Nature Communications, 8, 15381, https://doi.org/10.1038/ncomms15381, 2017.

Cohen, K. M., Finney, S. C., Gibbard, P. L., and Fan, J.-X.: The ICS International Chronostratigraphic Chart, Episodes, 36, 199-204, 2013, updated.

Domeier, M. and Torsvik, T. H.: Plate tectonics in the late Paleozoic, Geosci. Front. 5, 303-350, 2014.

Domeier, M., Van der Voo, R., and Torsvik, T. H.: Paleomagnetism and Pangea: the road to reconciliation, Tectonophysics, 514-517, 14-43, 2012.

Finnegan, S., Anderson, S. C., Harnik, P. G., Simpson, C., Byrnes, J. E., Tittensor, D. P., Finkel, Z. V., Lindberg, D. R., Liow, L. H., Lockwood, R., Lotze, H. K., McClain, C. R., McGuire, J. L., O'Dea, A., and Pandolfi, J. M.: Paleontological baselines for evaluating extinction risk in the modern oceans, Science, 348 , 567-570, https://doi.org/10.1126/science.aaa6635, 2015.

Fischer, V., Bardet, N., Benson, R. B. J., Arkhangelsky, M. S., and Friedman, M.: Extinction of fish-shaped marine reptiles associated with reduced evolutionary rates and global environmental volatility, Nature Communications, 7, 10825, https://doi.org/10.1038/ncomms10825, 2016.

Flament, N., Coltice, N., and Rey, P. F.: The evolution of the ${ }^{87} \mathrm{Sr} /{ }^{86} \mathrm{Sr}$ of marine carbonates does not constrain continental growth, Precambrian Res., 229, 177-188, 2013. 
Goddéris, Y., Donnadieu, Y., Le, Hir. G., and Lefebvre, V.: The role of palaeogeography in the Phanerozoic history of atmospheric $\mathrm{CO}_{2}$ and climate, Earth-Sci. Rev., 128, 122-138, 2014.

Golonka, J.: Cambrian-Neogene Plate Tectonic Maps, Wydawnictwa Uniwersytetu Jagielloñskiego, Kraków, 125 pp., 2000.

Golonka, J.: Late Triassic and Early Jurassic palaeogeography of the world, Palaeogeography, Palaeogeogr. Palaeocl., 244, 297307, 2007a.

Golonka, J.: Phanerozoic paleoenvironment and paleolithofacies maps: Mesozoic, Geologia / Akad. Gór.-Hut. im. Stanisława Staszica w Krakowie, 33, 211-264, 2007b.

Golonka, J.: Phanerozoic paleoenvironment and paleolithofacies maps: Cenozoic, Geologia / Akad. Gór.-Hut. im. Stanisława Staszica w Krakowie, 35, 507-587, 2009.

Golonka, J.: Paleozoic Paleoenvironment and Paleolithofacies Maps of Gondwana, AGH University of Science and Technology Press, Kraków, 2012.

Golonka, J., Ross, M. I., and Scotese, C. R.: Phanerozoic paleogeographic and paleoclimatic modeling maps, in: Pangea: Global Environment and Resources - Memoir 17, edited by: Embry, A. F., Beauchamp, B., and Glass, D. J., Canadian Society of Petroleum Geologists, Calgary, Alberta, Canada, 1-47, 1994.

Golonka, J., Krobicki, M., Pajak, J., Giang, N. V., and Zuchiewicz, W.: Global Plate Tectonics and Paleogeography of Southeast Asia, Faculty of Geology, Geophysics and Environmental Protection, AGH University of Science and Technology, Arkadia, Krakow, Poland, 2006.

Górski, K. M., Hivon, E., Banday, A. J., Wandelt, B. D., Hansen, F. K., Reinecke, M., and Bartelmann, M.: HEALPix: A Framework for High-Resolution Discretization and Fast Analysis of Data Distributed on the Sphere, Astrophys. J., 622: 759-771, 2005.

Gurnis, M., Müller R. D., and Moresi, L.: Dynamics of Cretaceous to the present vertical motion of Australia and the Origin of the Australian- Antarctic Discordance, Science, 279, 1499-1504, 1998.

Hallam, A. and Wignall, P. B.: Mass extinctions and their aftermath, Oxford University Press, Oxford, UK, 320 pp., 1997.

Hart, M. B.: Biotic recovery from mass extinction events, Geological Society of London, Special Publications, 102, 1996.

Heim, N. A., Knope, M. L., Schaal, E. K., Wang, S. C., and Payne, J. L.: Cope's Rule in the evolution of marine animals, Science, 347, 867-870, https://doi.org/10.1126/science.1260065, 2015.

Heine, C., Yeo, L. G., and Müller, R. D.: Evaluating global paleoshoreline models for the Cretaceous and Cenozoic, Aust. J. Earth Sci., 62, 275-287, 2015.

Kiessling, W., Flügel, E., and Golonka, J.: Patterns of Phanerozoic carbonate platform sedimentation, Lethaia, 36, 195-226, 2003.

Lenardic, A.: Plate tectonics: A supercontinental boost, Nat. Geosc., 10, https://doi.org/10.1038/ngeo2862, 2016.

Mannion, P. D., Benson, R. B. J., Carrano, M. T., Tennant, J. P., Judd, J., and Butler, R. J.: Climate constrains the evolutionary history and biodiversity of crocodylians, Nature Communications, 6, 8438, https://doi.org/10.1038/ncomms9438, 2015.

Matthews, K. J., Maloney, K. T., Zahirovic, S., Williams, S. E., Seton, M., and Müller, R. D.: Global plate boundary evolution and kinematics since the late Paleozoic, Global Planet. Change, 146, 226-250, 2016.
Müller, R. D., Seton, M.; Zahirovic, S.; Williams, S. E., Matthews, K. J., Wright, N. M., Shephard, G. E., Maloney, K. T., BarnettMoore, N., Hosseinpour, M., Dan, J. B., and John, C.: Ocean basin evolution and global-scale reorganization events since Pangea breakup, Annu. Rev. Earth Pl. Sc., 44, 107-138, 2016.

Nicholson, D. B., Holroyd, P. A., Benson, R. B. J., and Barrett, P. M.: Climate mediated diversification of turtles in the Cretaceous, Nature Communications, 6, 7848, https://doi.org/10.1038/ncomms8848, 2015.

Ronov, A. B.: Phanerozoic transgressions and regressions on the continents; a quantitative approach based on areas flooded by the sea and areas of marine and continental deposition, Am. J. Sci., 294, 777-801, 1994.

Ronov, A., Khain, V., and Seslavinsky, K.: Atlas of LithologicalPaleogeographical Maps of the World, Late Precambrian and Paleozoic of Continents, U.S.S.R. Academy of Sciences, Leningrad, 70 pp., 1984.

Ronov, A., Khain, V., and Balukhovsky, A.: Atlas of LithologicalPaleogeographical Maps of the World, Mesozoic and Cenozoic of Continents and Oceans, U.S.S.R. Academy of Sciences, Leningrad, 79 pp., 1989.

Salles, T., Flament, N., and Müller, D.: Influence of mantle flow on the drainage of eastern Australia since the Jurassic Period, Geochem. Geophy. Geosy., 18, 280-305, https://doi.org/10.1002/2016GC006617, 2017.

Scotese, C. R.: Paleogeographic Atlas, PALEOMAP project, Arlington, Texas, USA, 1997.

Scotese, C. R.: Atlas of Earth History, Volume 1, Paleogeography, PALEOMAP project, Arlington, Texas, 52 pp., 2001.

Scotese, C.: A continental drift flipbook, J. Geol., 112, 729-741, https://doi.org/10.1086/424867, 2004.

Sloss, L. L.: Tectonic evolution of the craton in Phanerozoic time, in: Sedimentary cover-North American craton: U.S., edited by: Sloss, L. L., The Geology of North America, D-2, Geological Society of America, 25-51, 1988.

Smith, A. B., Lloyd, G. T., and McGowan, A. J.: Phanerozoic marine diversity: rock record modelling provides an independent test of large-scale trends, P. Roy. Soc. B-Biol. Sci., 279, 44894495, 2012.

Smith, A. G., Smith, D. G., and Funnell, B. M.: Atlas of Mesozoic and Cenozoic Coastlines, Cambridge University Press, Cambridge, 99 pp, 1994.

Spasojevic, S. and Gurnis, M.: Sea level and vertical motion of continents from dynamic Earth models since the Late Cretaceous, AAPG Bull., 96, 2037-2064, https://doi.org/10.1306/03261211121, 2012.

Stampfli, G. M., Hochard, C., Vérard, C., Wilhem, C., and vonRaumer, J.: The formation of Pangea, Tectonophysics, 593, 1-19, 2013.

Tennant, J. P., Mannion, P. D., Upchurch, P.: Sea level regulated tetrapod diversity dynamics through the Jurassic/Cretaceous interval, Nature Communications, 7, 12737, https://doi.org/10.1038/ncomms12737, 2016.

Vai, G. B.: Development of the palaeogeography of Pangaea from Late Carboniferous to Early Permian, Palaeogeogr. Palaeocl., 196, 125-155, 2003.

Valentine, J. W., Jablonski, D., Kidwell, S., and Roy, K.: Assessing the fidelity of the fossil record by using marine bivalves, P. Natl. Acad. Sci. USA, 103, 6599-6604, 2006. 
van der Meer, D. G., van den Berg van Saparoea, A. P. H., van Hinsbergen, D. J. J., van de Weg, R. M. B., Godderis, Y., Le Hir, G., and Donnadieu, Y.: Reconstructing first-order changes in sea level during the Phanerozoic and Neoproterozoic using strontium isotopes, Gondwana Res., 44, 22-34, 2017.

Veevers, J. J.: Gondwanaland from 650-500 Ma assembly through 320 Ma merger in Pangea to 185-100 Ma breakup: supercontinental tectonics via stratigraphy and radiometric dating, EarthSci. Rev., 68, 1-132, 2004.

Vérard, C., Hochard, C., Baumgartner, P. O., and Stampfli, G. M.: 3D palaeogeographic reconstructions of the Phanerozoic versus sea-level and Sr-ratio variations, Journal of Palaeogeography, 4, 167-188, 2015.

Walker, L. J., Wilkinson, B. H., and Ivany, L. C.: Continental drift and Phanerozoic carbonate accumulation in shallow-shelf and deep-marine settings, J. Geol., 110, 75-87, https://doi.org/10.1086/324318, 2002
Wichura, H., Jacobs, L. L., Lin, A., Polcyn, M. J., Manthi, F. K., Winkler, D. A., Strecker, M. R., and Clemens, M.: A 17-Myold whale constrains onset of uplift and climate change in east Africa, P. Natl. Acad. Sci. USA, 112, 3910-3915, 2015.

Wright, N., Zahirovic, S., Müller, R. D., and Seton, M.: Towards community-driven paleogeographic reconstructions: integrating open-access paleogeographic and paleobiology data with plate tectonics, Biogeosciences, 10, 1529-1541, https://doi.org/10.5194/bg-10-1529-2013, 2013.

Yeh, M. W. and Shellnutt, J. G.: The initial break-up of Pangæa elicited by Late Palæozoic deglaciation, Scientific Reports, 6, 31442, https://doi.org/10.1038/srep31442, 2016.

Zaffos, A., Finnegan, S., and Peters, S. E.: Plate tectonic regulation of global marine animal diversity, P. Natl. Acad. Sci. USA, 114, 5653-5658, https://doi.org/10.1073/pnas.1702297114, 2017. 